\title{
Magnetic MOF for AO7 Removal and Targeted Delivery
}

\author{
Xue-Qing Zhan ${ }^{1,+}{ }^{+}$Xiao-Yan Yu ${ }^{1,+}{ }^{\text {, Fang-Chang Tsai }}{ }^{1, *}{ }^{\mathbb{D}}$, Ning Ma ${ }^{2}$, Huan-Li Liu ${ }^{1}$, Yu Han ${ }^{1}$, \\ Lei Xie ${ }^{1}$, Tao Jiang ${ }^{1}$, Dean Shi ${ }^{1, *}$ and Yan Xiong ${ }^{3, *}$ \\ 1 Hubei Key Laboratory of Polymer Materials, Key Laboratory for the Green Preparation and Application of \\ Functional Materials (Ministry of Education), Hubei Collaborative Innovation Center for Advanced Organic \\ Chemical Materials, School of Materials Science and Engineering, Hubei University, Wuhan 430062, China; \\ m18272163856@163.com (X.-Q.Z.); m13477071614@163.com (X.-Y.Y.); pangchoudan521@163.com (H.-L.L.); \\ 15071465309@163.com (Y.H.); raytse526@163.com (L.X.); jiangtao@hubu.edu.cn (T.J.) \\ 2 Department of Chemistry, Wuhan University, Wuhan 430072, China; maning@whu.edu.cn \\ 3 School of Physics and Optoelectronic Engineering, Yangtze University, Jingzhou 434023, China \\ * Correspondence: tfc0323@gmail.com (F.-C.T.); deanshi2012@yahoo.com (D.S.); \\ xiongyan1215@163.com (Y.X.); Tel.: +86-2788661729 (F.-C.T.); Fax: +86-2788661729 (F.-C.T.) \\ + These authors contributed equally to this work.
}

Received: 25 May 2018; Accepted: 13 June 2018; Published: 15 June 2018

check for updates

\begin{abstract}
Owing to their high surface area and porosity, metal-organic frameworks (MOFs) have been gradually employed for a myriad of applications ranging from sensing, pollutant adsorption, and drug delivery to environmental remediation and catalysis. Magnetic nanoparticles-metal-organic frameworks (MMOFs) hybrid materials can facilitate facile removal of MOFs from solutions. In this report, we report the synthesis of $\mathrm{Fe}_{3} \mathrm{O}_{4} @ \mathrm{UiO}-66$ by encapsulation and simulated the drug loading and release by studying the adsorption and release of AO7. Thus, we loaded these MMOFs with $\mathrm{AO} 7$ and found that they were able to trigger and control its release by simply applying an external magnetic field. The magnetic field heats the magnets in the MOF, which causes the load to burst from the framework.
\end{abstract}

Keywords: magnetic MOFs; triggered release; targeted delivery; AO7

\section{Highlights}

- We have synthesized magnetic $\mathrm{MOF}, \mathrm{Fe}_{3} \mathrm{O}_{4} @ \mathrm{UiO}-66$ through encapsulation.

- The $\mathrm{Fe}_{3} \mathrm{O}_{4} @ \mathrm{UiO}-66$ composite material was found to have comparable loading capacity $(140 \mathrm{mg} / \mathrm{g})$ to the conventional UiO-66 (140 mg/g).

- $\quad$ The $\mathrm{Fe}_{3} \mathrm{O}_{4} @ \mathrm{UiO}-66$ can be filled with AO7, which is released when a magnetic field is applied.

\section{Introduction}

Magnetic metal-organic frameworks [1] (MMOFs), comprising of magnetic nanoparticles and MOFs [2-4], have attracted tremendous of interests from researchers in the past decade [5,6]. Such materials have the benefits of the nanocharacteristics of MOFs, which in turn allows for expanding the scope of MOFs' applications. Such active nanoparticles include quantum dots [7], metal nanoparticles/nanorods [8], graphene [9,10], porous silica nanoparticles [11,12], and magnetic beads [13], which have been applied in catalysis, optics, sensing, liquid phase separation and adsorption, etc. [14]. MMOFs have the following advantages: (I) the application of MMOFs is enhanced through selecting a suitable target material, and the regulation of synthesis conditions can yield materials for specific applications (such as catalysis, adsorption, and release) [15]. (II) It overcomes the shortcomings of the simple magnetic particles' lack of selectivity and the accumulation in the magnetic variation. The rate of diffusion and mass transfer characteristics can 
be modulated by the structures of MMOFs. (III) The innovations herein were used to produce virtually every MMOF by a one-pot synthesis method [16]. For example, in environmental testing, it is difficult to recycle MOFs and target analytes in a complex medium without other means. However, after the MMOF is enriched for the target analyte, they can be recovered from the aqueous phase or water/soil suspension by applying a magnetic field [17]. MMOFs can be directly injected after elution to avoid the extraction, purification, elution process, which saves significant analysis time. (IV) Increased reusability. Used MMOF materials can be recycled after certain treatment, which is consistent with the green concept.

Magnetic nanoparticles/nanorods are typically made of iron, cobalt, nickel, and their oxides [18]. Magnetic particles commonly used in practical applications are ferroxide with ferromagnetism or superparamagnetism [19], such as $\mathrm{Fe}_{3} \mathrm{O}_{4}$ and $\gamma-\mathrm{Fe}_{2} \mathrm{O}_{3}$. However, the unprocessed $\mathrm{Fe}_{3} \mathrm{O}_{4}$ and $\gamma-\mathrm{Fe}_{2} \mathrm{O}_{3}$ are easily oxidized and less selective. In the actual application process, agglomeration may occur due to residual magnetism, which will lead to decreased efficiency [19]. Therefore, in order to realize the full potential of the magnetic hybrid materials, nanoparticles/nanorods, suitable inorganic or organic coatings are often coated on the surface of magnetic nanoparticles/nanorods [14]. In the synthesis of MMOFs, the MOFs will grow, attach or coat onto magnetic particles or nanorods. According to the interaction between magnetic particles and MOFs, the main synthetic methods for production can be divided into four categories [5], including embedding [20], layer-by-layer [21], encapsulation method [13], and mixed method [22].

The synergistic effects of MOFs and the magnetic particles enable the application of MMOFs for targeted delivery of NPs to the site of interest with the guidance of an externally applied magnetic field [23-26]. Therefore, MMOF materials have tremendous value in biomedical applications [27-29]. Compared with the original MOF material, MMOF material with magnetic particles has better selectivity, catalysis, and magnetism, which is easier to locate or collect. This makes the adsorption and other operations simple, fast, and efficient, greatly improving the operability of such materials [30-32]. Compared with the traditional adsorbents to drugs, the magnetic adsorbent separates [33] and pre-enriches the sample under the applied magnetic field and reduces the consumption of the sample and the reagent.

In this work, we reported a composite of magnetic $\mathrm{Fe}_{3} \mathrm{O}_{4}$ and UiO-66 [34]. Encapsulation is a method to prepare MMOFs which mainly utilizes the buffer interface between the porous framework and the magnetic particles to promote the growth of MOFs around the magnetic particles [5]. To improve the compatibility of MMOFs, magnetic particles are pre-embedded in the polymer layer and then added to the MOFs as the nucleation site for the growth of MOFs. The adsorption and release of $\mathrm{AO} 7$ were studied to simulate the drug loading and release of $\mathrm{Fe}_{3} \mathrm{O}_{4} @ \mathrm{UiO}-66$. As can be seen from Figure 1, the synthesis course of the composite and the structural model of $\mathrm{Fe}_{3} \mathrm{O}_{4} @ \mathrm{UiO}-66$ is clear. While in our work, the $\mathrm{Fe}_{3} \mathrm{O}_{4} @ \mathrm{UiO}-66$ adsorbents for adsorption of dye were synthesized by a one-pot method. Compared to layer-by-layer methods, the synthesis is energy conservative and reduces emissions which correspond to the concept of Green Chemistry. Furthermore, we tested the magnetic properties of $\mathrm{Fe}_{3} \mathrm{O}_{4} @ \mathrm{UiO}-66$ and studied the composite's adsorption and release of $\mathrm{AO} 7$ at $37^{\circ} \mathrm{C}$. 


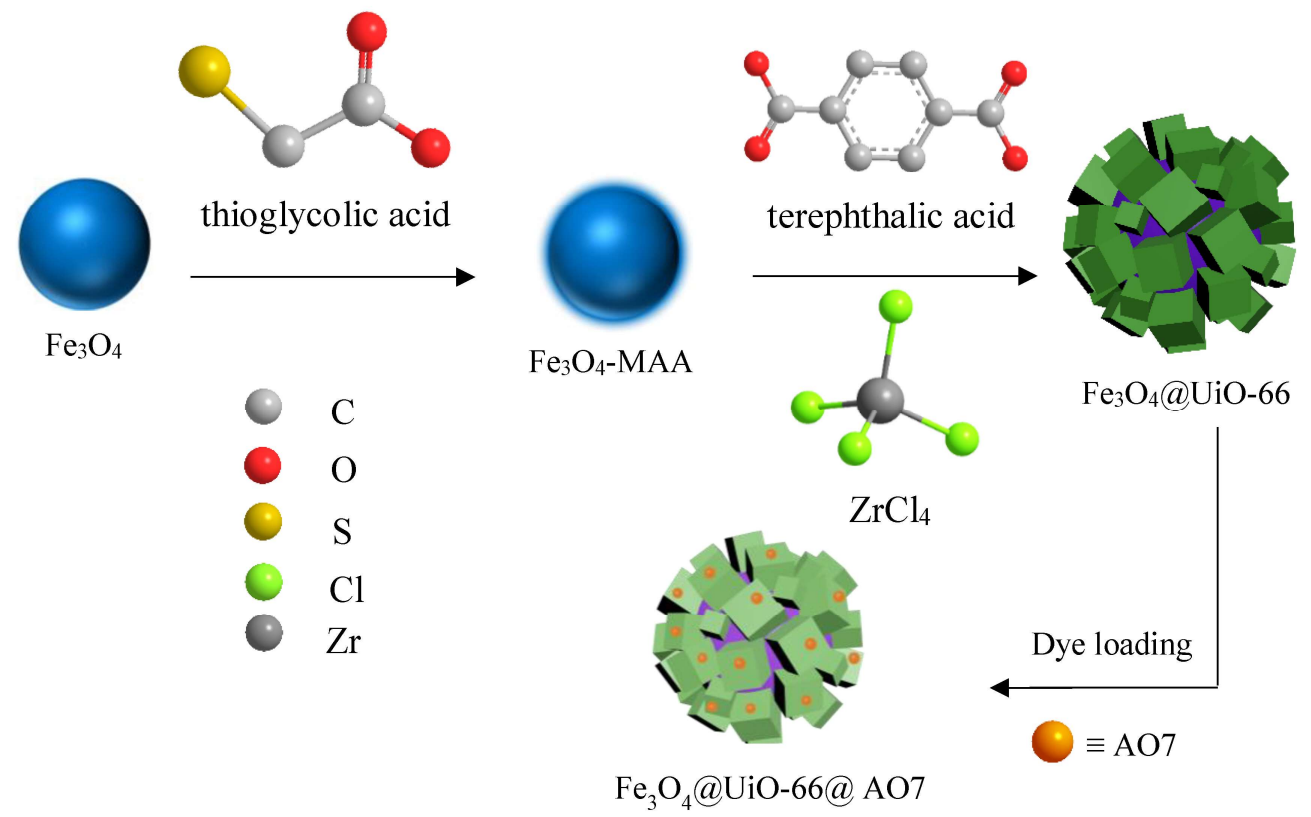

Figure 1. The concept of synthesis of $\mathrm{Fe}_{3} \mathrm{O}_{4} @ \mathrm{UiO}-66$.

\section{Experiment}

\subsection{Materials}

All chemicals and reagents used were of analytical grade. Ferric chloride hexahydrate $\left(\mathrm{FeCl}_{3} \cdot 6 \mathrm{H}_{2} \mathrm{O}\right)$ was purchased from Chengdu kelong chemical reagent plant (Chengdu, China). Iron (II) dichloride tetrahydrate $\left(\mathrm{FeCl}_{2} \cdot 4 \mathrm{H}_{2} \mathrm{O}\right)$ was purchased from Tianjin Guangfu fine chemical research institute (Tianjin, China). Zirconium (IV) chloride $\left(\mathrm{ZrCl}_{4}\right)$ was purchased from Aladdin (Aladdin Industrial Cooperation, Shanghai, China). Terephthalic acid, N,N-Dimethylformamidel, ammonium hydroxide, thioglycolic acid, polyethylene glycol, and Orange II sodium salt (AO7) were purchased from Sinopharm Chemical Reagent Co., Ltd. (Shanghai , China).

\subsection{Synthesis of Samples}

Synthesis of $\mathrm{Fe}_{3} \mathrm{O}_{4} \mathrm{Fe}_{3} \mathrm{O}_{4}$ nanoparticles were synthesized in accord to a reported procedure [35]. Ferric chloride hexahydrate $(2.43 \mathrm{~g})$, iron dichloride tetrahydrate $(1.19 \mathrm{~g})$, and polyethylene glycol $(1.00 \mathrm{~g})$ were dissolved in $100 \mathrm{~mL}$ deionized water under $\mathrm{N}_{2}$ atmosphere. Ammonium hydroxide was added to the solution with stirring until the $\mathrm{pH}$ reached 11. Then, the solution was stirred for $30 \mathrm{~min}$ at $50{ }^{\circ} \mathrm{C}$, follow by sonication for $30 \mathrm{~min}$ before being heated to $80^{\circ} \mathrm{C}$ for $1 \mathrm{~h}$. The precipitation was separated by magnetism and washed with distilled water until neutral. Finally, the product was dried under vacuum for $4 \mathrm{~h}$.

Synthesis of $\mathrm{Fe}_{3} \mathrm{O}_{4}$-MAA The deposition of $\mathrm{Fe}_{3} \mathrm{O}_{4}(0.50 \mathrm{~g})$ was dispersed in $50 \mathrm{~mL}$ mercaptoacetic acid (MAA) solution ( $2.9 \mathrm{mmol}$ ) in ultrasound for $15 \mathrm{~min}$, and then the solution was stirred for $24 \mathrm{~h}$ at room temperature [36]. The particle was washed with ethanol and deionized water respectively with the help of magnet, and then dried in vacuum oven for $4 \mathrm{~h}$.

Synthesis of $\mathrm{Fe}_{3} \mathrm{O}_{4} @ \mathrm{UiO}-66$ We synthesized $\mathrm{Fe}_{3} \mathrm{O}_{4} @ \mathrm{UiO}-66$ according to the literature [37]. Briefly, $0.05 \mathrm{~g} \mathrm{Fe}_{3} \mathrm{O}_{4}$-MAA was dispersed in $58 \mathrm{~mL} \mathrm{DMF}$, and then $0.12 \mathrm{~g} \mathrm{ZrCl}_{4}$ and $0.134 \mathrm{~g} \mathrm{H}_{2} \mathrm{BDC}$ were added. The mixture was in ultrasound for $20 \mathrm{~min}$. Then, the solution was mechanically stirred for $24 \mathrm{~h}$ at $120^{\circ} \mathrm{C}$. The sample was washed by DMF and ethanol, respectively. The ultimate product was dried in vacuum at $90^{\circ} \mathrm{C}$. 


\subsection{Adsorption and Release Experiment}

The adsorption experiments were executed at $37^{\circ} \mathrm{C}$. Ten $\mathrm{mg}$ samples were added to a series of AO7 solutions with concentrations of 10, 20,30, and $40 \mathrm{ppm}(50 \mathrm{~mL})$ to measure the adsorption kinetics. The amount of AO7 in solution was monitored by UV-vis spectrometry by using a calibration curve based on the Lambert-Beer law:

$$
\mathrm{A}=0.0581 \mathrm{C}_{t}+0.0465
$$

where $\mathrm{A}$ is the absorbance and $\mathrm{C}_{t}$ is the concentration of $\mathrm{AO}$ solution $(\mathrm{mg} / \mathrm{L})$. Then, the amount of the absorbed dye: $q_{t}(\mathrm{mg} / \mathrm{g})$ was calculated by the following equation:

$$
q_{t}=\left(\mathrm{C}_{0}-\mathrm{C}_{t}\right) \mathrm{V}_{0} / \mathrm{m}
$$

where $C_{0}$ is the initial concentration of the solution $(\mathrm{mg} / \mathrm{L}) ; \mathrm{C}_{t}$ is the concentration of the solutions at time $(t) ; \mathrm{V}_{0}$ is the volume of the solution $(\mathrm{mL}) ; \mathrm{m}$ is the mass of the adsorbent $(\mathrm{g})$.

Adsorbed $\mathrm{Fe}_{3} \mathrm{O}_{4} @ \mathrm{UiO}-66$ with loaded $\mathrm{AO} 7$ was treated with methanol under circumstance of $37^{\circ} \mathrm{C}$. Five $\mathrm{mg}$ different concentrations of adsorbed $\mathrm{Fe}_{3} \mathrm{O}_{4} @ \mathrm{UiO}-66$ was respectively added to $20 \mathrm{~mL}$ methanol to study the release of AO7.

\section{Characterization}

Morphology was collected by a field emission scanning electron microscope (SEM) JSM7100F (Hitachi, Tokyo, Japan).

Powder X-ray diffraction (PXRD) patterns were obtained using a Rigaku X-ray Diffractometer Model D/MAX_IIIC (Bruker, Billerica, MA, Germany). Measurements were made over a range of $4^{\circ}<2 \theta<40^{\circ}$ in 0.02 step size at a scanning rate of $10 \mathrm{deg} / \mathrm{min}$.

Fourier transform infrared spectroscopy (FT-IR) spectra of products were recorded on NICOLET iS50 FT-IR spectrometer (Thermo Fisher, Waltham, MA, USA).

The magnetic properties were characterized over a range of $0 \sim 1.5 \mathrm{~T}$ under room temperature by a multi-function vibrating sample magnetometer (VSM) JDAW-2000D (Yingpu, Changchun, China).

V-Sorb 2800 TP surface area and pore size analyzer (GAPP, Beijing, China) was used to measure the $\mathrm{N} 2$ adsorption-desorption isotherms of samples at $77 \mathrm{~K}$.

The absorbance measurements of all AO7 aqueous solution were performed on a TU-1810DSPC UV-vis spectrometer (Beijing Purkinje General Instrument Co., Ltd., Beijing, China).

\section{Results and Discussion}

$\mathrm{Fe}_{3} \mathrm{O}_{4} @ \mathrm{UiO}-66$ was synthesized by encapsulating $\mathrm{Fe}_{3} \mathrm{O}_{4}$ NPs with UiO-66. It can be seen from Figure $2 \mathrm{~b}$ that $\mathrm{UiO}-66$ particles are wrapped outside $\mathrm{Fe}_{3} \mathrm{O}_{4}$ and the particle size of the composite is $\sim 2 \mu \mathrm{m}$. The morphology of the composite has an obvious change after encapsulation when compared to the original UiO-66 (Figure 2a). The FT-IR spectrum of intermediate products and final products is depicted in Figure 2c, which verifies the progress of modification. The curves are the description of $\mathrm{Fe}_{3} \mathrm{O}_{4}, \mathrm{Fe}_{3} \mathrm{O}_{4}$-MAA, and $\mathrm{Fe}_{3} \mathrm{O}_{4} @ \mathrm{UiO}-66$, respectively. In curve a, the peak at $568 \mathrm{~cm}^{-1}$ matches with $\mathrm{v}(\mathrm{Fe}-\mathrm{O})$ [38]. The adsorption bands of symmetric and anti-symmetric stretching vibration at $2923 \mathrm{~cm}^{-1}$ and $2853 \mathrm{~cm}^{-1}$ correspond to $C$ - $H$ observed for in curve $b$, which represents the presence of the carbon hydrogen bonds of thioglycolic acid. And the peaks at $1618 \mathrm{~cm}^{-1}$ and $3380 \mathrm{~cm}^{-1}$ represent the carboxyl group and the water. Comparing curve $b$ with curve $a$, we see that mercaptoacetic acid has been successfully received on $\mathrm{Fe}_{3} \mathrm{O}_{4}$. In curve c, the characteristic absorption bands of $\mathrm{N}-\mathrm{H}$ in DMF emerged at $1656 \mathrm{~cm}^{-1}$. Moreover, the symmetric and anti-symmetric stretching vibration peaks of carboxyl groups were at $1585 \mathrm{~cm}^{-1}$ and $1398 \mathrm{~cm}^{-1}$, and at $746 \mathrm{~cm}^{-1}$, the characteristic vibration of $\mathrm{Zr}-\mathrm{O}$ emerged [37], confirming the presence of UiO-66, and verifying the successful complexation of $\mathrm{UiO}-66$ and $\mathrm{Fe}_{3} \mathrm{O}_{4}$. Our results show that the method of modifying $\mathrm{Fe}_{3} \mathrm{O}_{4}$ with thioglycolic acid is feasible. 
To confirm the structural integrity of the UiO-66 contained in $\mathrm{Fe}_{3} \mathrm{O}_{4} @ \mathrm{UiO}-66$, the PXRD of the composite material was collected and compared with the simulation of UiO-66 (Figure 2c). As can be seen from Figure 2d, comparison of the composite with the simulation showed that the crystal diffraction peak is visible and consistent with the simulation. This provides evidence for practicality of the preparation of porous composite materials involving $\mathrm{Fe}_{3} \mathrm{O}_{4}$ modified by MAA as the crystal nucleus in precursor UiO-66 solution.

(a)

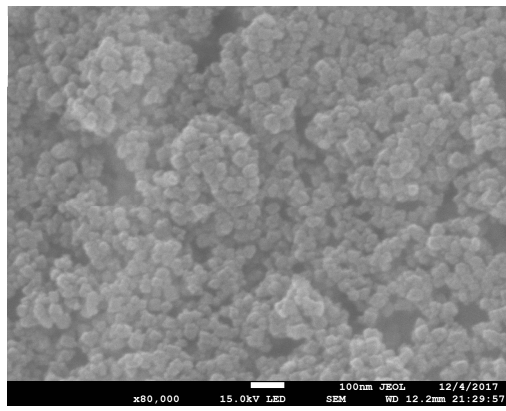

(c)

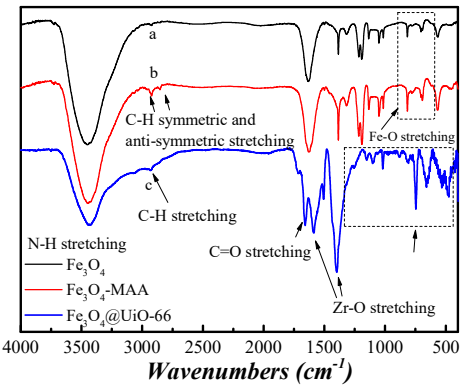

(b)

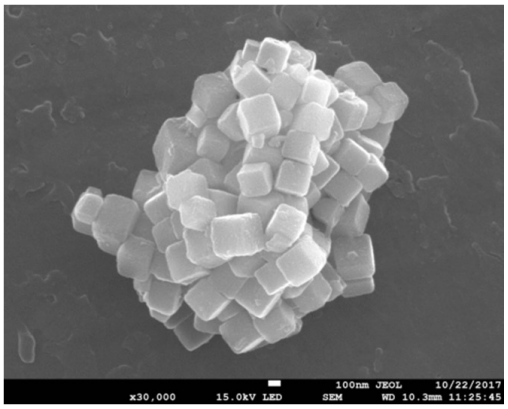

(d)

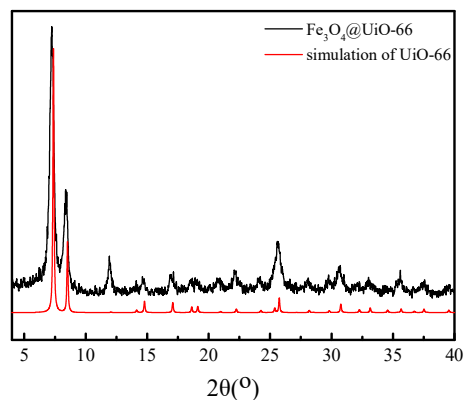

Figure 2. Field emission SEM image of (a) UiO-66 and (b) $\mathrm{Fe}_{3} \mathrm{O}_{4} @ \mathrm{UiO}-66$ composite, (c) FT-IR of $\mathrm{Fe}_{3} \mathrm{O}_{4}$, $\mathrm{Fe}_{3} \mathrm{O}_{4}$-MAA and $\mathrm{Fe}_{3} \mathrm{O}_{4} @ U$ UiO-66, (d) PXRD patterns of $\mathrm{Fe}_{3} \mathrm{O}_{4} @ U i O-66$ and simulation of UiO-66.

As shown in Figure 3, to evaluate the magnetic properties of $\mathrm{Fe}_{3} \mathrm{O}_{4} @ \mathrm{UiO}-66$, the magnetic measurements were performed in a magnetic field range from -15 to $+15 \mathrm{kOe}$ at room temperature. The saturation magnetization of the $\mathrm{Fe}_{3} \mathrm{O}_{4} @ \mathrm{UiO}-66$ was $6.51 \mathrm{emu} / \mathrm{g}$, smaller than that of the pristine $\mathrm{Fe}_{3} \mathrm{O}_{4}$ nanoparticles (70.31 emu/g) due to the encapsulation within the UiO-66 layer. Both curves present a magnetic hysteresis loop (Figure 3), which demonstrated the strong superparamagnetic character of the as-synthesized $\mathrm{Fe}_{3} \mathrm{O}_{4} @ \mathrm{UiO}-66$ composites. Furthermore, it is convenient to control the location of separation and release after absorption. Finally, from the video (Supplementary Materials) we can see that the $\mathrm{Fe}_{3} \mathrm{O}_{4} @ \mathrm{UiO}-66$ solution could be quickly collected using the magnet. Because of which, $\mathrm{Fe}_{3} \mathrm{O}_{4} @ \mathrm{UiO}-66$ can be magnetically recovered and the cost is relatively reduced.

(a)

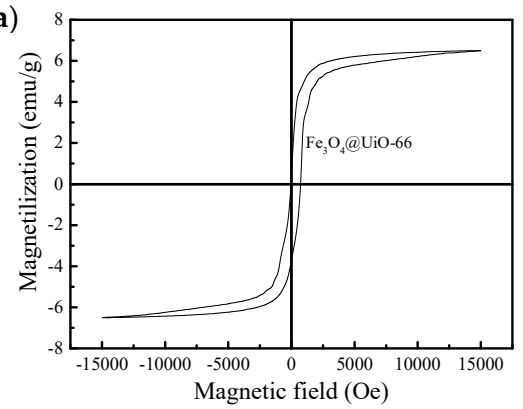

(b)

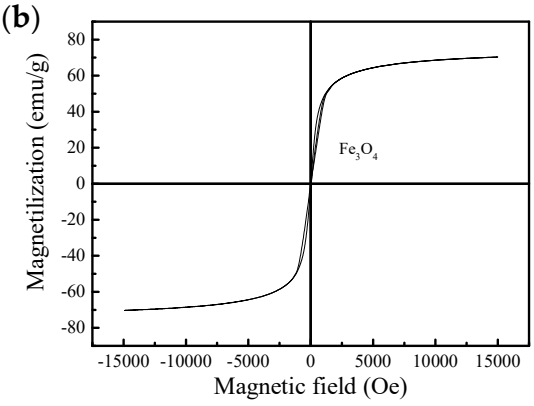

Figure 3. Magnetization hysteresis curves of (a) $\mathrm{Fe}_{3} \mathrm{O}_{4} @ \mathrm{UiO}-66$ and (b) $\mathrm{Fe}_{3} \mathrm{O}_{4}$. 
As illustrated in Figure 4, the BET surface area and pore distribution were calculated from the $\mathrm{N}_{2}$ adsorption isotherms measured at $77 \mathrm{~K}$. The original UiO-66 has a larger surface area $\left(793 \mathrm{~m}^{2} / \mathrm{g}\right)$ than $\mathrm{Fe}_{3} \mathrm{O}_{4} @$ UiO-66 (429 m²/g) due to the encapsulation, as shown at Figure 4a,b. As a result of the core-shell structure of $\mathrm{Fe}_{3} \mathrm{O}_{4} @ \mathrm{UiO}-66, \mathrm{Fe}_{3} \mathrm{O}_{4}$ particles were wrapped in UiO-66, thus giving rise to the pore volume increases. $\mathrm{Fe}_{3} \mathrm{O}_{4}$ particles occupied the channel, accounting for large volume but low available volume. As indicated in Figure 4c,d, UiO-66 and the composite $\mathrm{Fe}_{3} \mathrm{O}_{4} @ \mathrm{UiO}-66$ are all mesoporous materials.

(a)

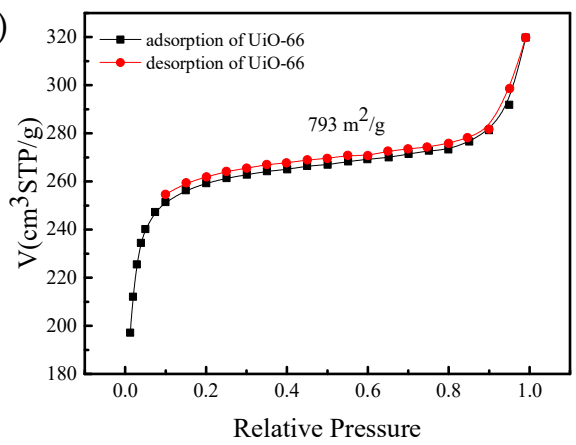

(c)

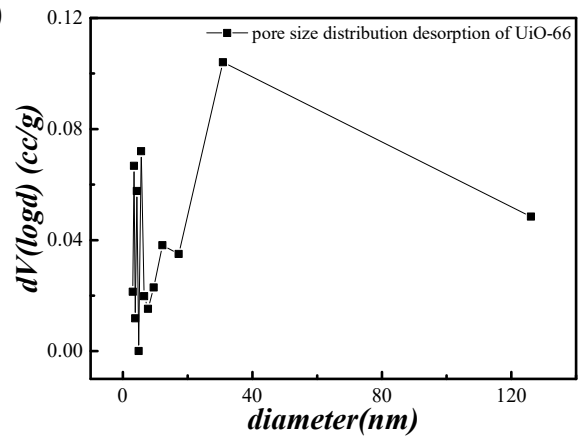

(b)

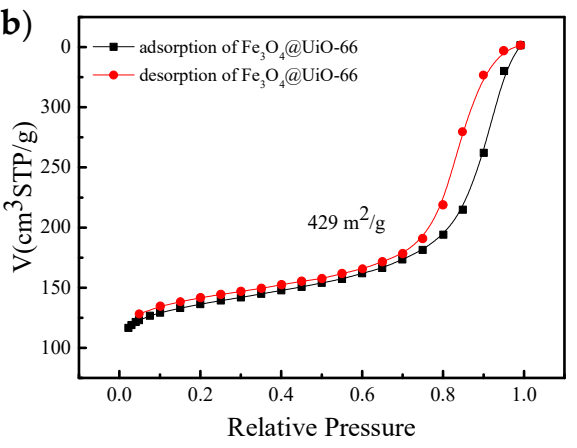

(d)

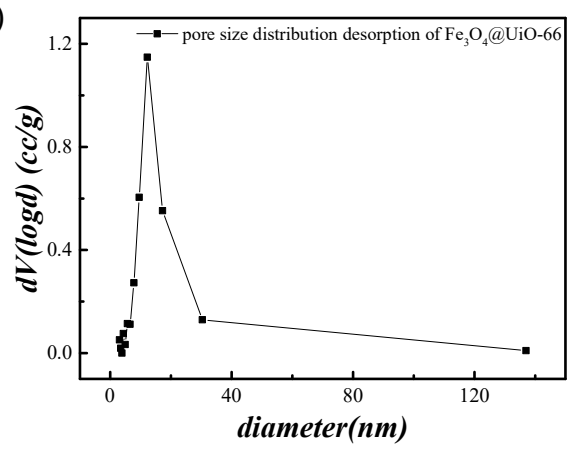

Figure 4. $\mathrm{N}_{2}$ isothermal adsorption UiO-66 (a) and $\mathrm{Fe}_{3} \mathrm{O}_{4} @ \mathrm{UiO}-66$ (b), pore size distribution desorption of UiO-66 (c) and $\mathrm{Fe}_{3} \mathrm{O}_{4} @ \mathrm{UiO}-66(\mathbf{d})$.

As shown in Figure 5a, the adsorption of $\mathrm{Fe}_{3} \mathrm{O}_{4} @ \mathrm{UiO}-66$ with a very fast growth rate was complete within $5 \mathrm{~h}$, and with the passage of time, the adsorption rate of $\mathrm{Fe}_{3} \mathrm{O}_{4} @ \mathrm{UiO}-66$ slowed down and reached a plateau at $140 \mathrm{mg} / \mathrm{g}$. AO7 [39,40] is an acidic dye, the composite mainly relies on Lewis acid-base interaction between $\mathrm{AO} 7$ and $\mathrm{Zr}$-based MOFs [34]. Figure $5 \mathrm{c}$ shows the release profile of $\mathrm{Fe}_{3} \mathrm{O}_{4} @$ UiO- 66 with $\mathrm{AO}$, which is quite fast and releases $60 \%$ within $5 \mathrm{~h}$ which is affected by natural diffusion [34,41]. The presence of methanol promotes the decomposition of $\mathrm{Fe}_{3} \mathrm{O}_{4} @ \mathrm{UiO}-66$ and the dye, accelerating the rate of dye release. Current environmental awareness is gradually changing attitudes and regulations, such as the new drug removal/release regulations (magnetic MOF for AO7), and are gradually beginning to reverse the situation. Compared with Figure $5 \mathrm{a}-\mathrm{d}$, although the adsorption capacity of UiO-66 and $\mathrm{Fe}_{3} \mathrm{O}_{4} @ \mathrm{UiO}-66$ is approximate, regarding the release rate, $\mathrm{Fe}_{3} \mathrm{O}_{4} @ \mathrm{UiO}-66$ is faster than UiO-66 in the initial release. These findings go against our hypothesis that the magnetic field heats the magnets in the MOF, which causes the load to burst from the framework.

AO7 is an acidic dye with benzene. Meanwhile, aspirin is a similar acid medication used as a painkiller and Iressa is a small molecule with benzene for the treatment of tumors. Due to the magnetic control of $\mathrm{Fe}_{3} \mathrm{O}_{4} @$ UiO-66, the drug-loaded composite can be targeted to release the drug in the human. Body fluids in humans are predominantly neutral or weakly basic, which slightly slows the rate of drug release. That means drugs will be released more slowly in the human body, which will be more beneficial to drugs being absorbed by the body. 
(a)

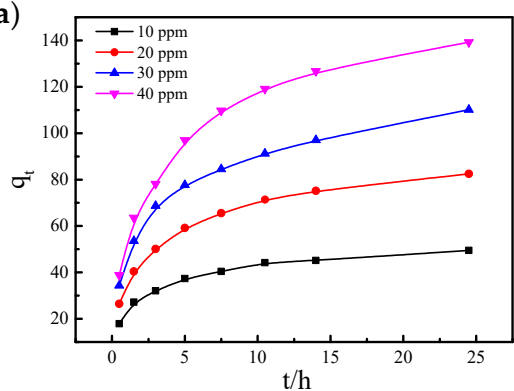

(c)

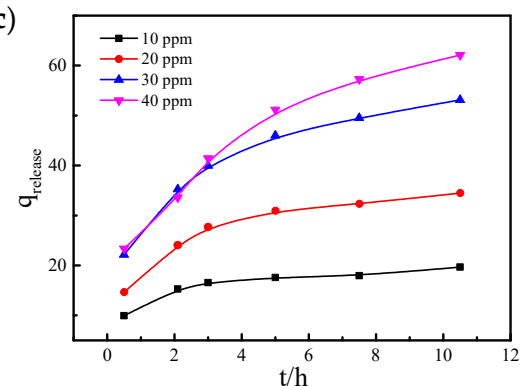

(b)

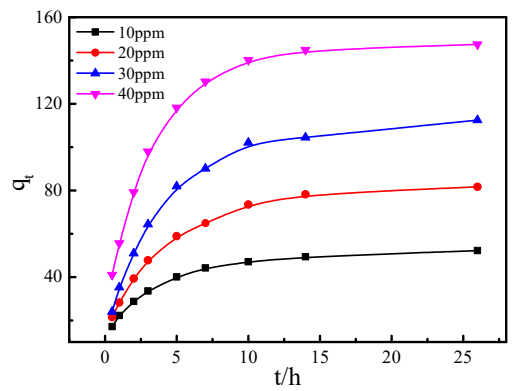

(d)

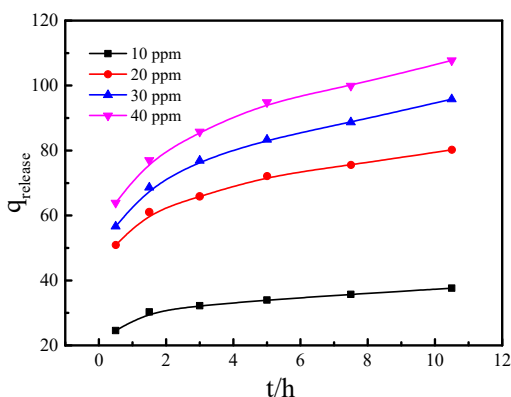

Figure 5. Adsorption kinetics of $\mathrm{AO} 7$ as a function of initial $\mathrm{AO} 7$ concentration using $(\mathbf{a}) \mathrm{Fe}_{3} \mathrm{O}_{4} @ \mathrm{UiO}-66$ and (b) UiO-66; desorption kinetics of $\mathrm{AO} 7$ as a function of initial AO7 concentration using (c) $\mathrm{Fe}_{3} \mathrm{O}_{4} @ \mathrm{UiO}-66$ and (d) UiO-66.

\section{Conclusions}

In summary, we have synthesized $\mathrm{Fe}_{3} \mathrm{O}_{4} @ \mathrm{UiO}-66$ by encapsulating $\mathrm{Fe}_{3} \mathrm{O}_{4}$ into UiO-66. The incorporation of magnetic $\mathrm{Fe}_{3} \mathrm{O}_{4}$ enables facile removal of adsorbent. The dye was adsorbed and released at $37^{\circ} \mathrm{C}$, the $\mathrm{Fe}_{3} \mathrm{O}_{4} @ \mathrm{UiO}-66$ composite material was found to have an approximate loading capacity $(140 \mathrm{mg} / \mathrm{g}$ ) comparable to the conventional $\mathrm{UiO}-66(140 \mathrm{mg} / \mathrm{g})$ and the release rate of the dye under the action of methanol are also considerable. By comparing the properties and structure of AO7 with similar drugs, we think some drugs such as Aspirin and Iressa can also be adsorbed by $\mathrm{Fe}_{3} \mathrm{O}_{4} @ \mathrm{UiO}-66$. Because of the effect of $\mathrm{pH}$ on drug release, the rate of release is somewhat slowed down, which ensures that the drug is better absorbed by the body. Some promising applications in industrial sustainability, medical processes, and environment-related areas are also discussed.

Supplementary Materials: The following are available online at http:/ / www.mdpi.com/2073-4352/8/6/250/s1, Video: $\mathrm{Fe}_{3} \mathrm{O}_{4} @ \mathrm{UiO}-66$ dispersion in the presence of a magnet field.

Author Contributions: The manuscript was written through contributions of all authors. All authors have given approval to the final version of the manuscript.

Acknowledgments: This study has been supported by the National High Technology Research and Development Program (863 program) of China No. 2012AA06A111; Hubei Provincial Natural Science Foundation of China No. 2014CFB552; Hubei Collaborative Innovation Center for Advanced Organic Chemical Materials of China No. 000-01647909.

Conflicts of Interest: The authors declare no conflict of interest.

\section{References}

1. Minguez Espallargas, G.; Coronado, E. Magnetic functionalities in MOFs: From the framework to the pore. Chem. Soc. Rev. 2018, 47, 533-557. [CrossRef] [PubMed]

2. Long, J.R.; Yaghi, O.M. The pervasive chemistry of metal-organic frameworks. Chem. Soc. Rev. 2009, 38, 1213-1214. [CrossRef] [PubMed] 
3. Maurin, G.; Serre, C.; Cooper, A.; Ferey, G. The new age of MOFs and of their porous-related solids. Chem. Soc. Rev. 2017, 46, 3104-3107. [CrossRef] [PubMed]

4. Farha, O.K.; Hupp, J.T. Rational Design, Synthesis, Purification, and Activation of Metal-Organic Framework Materials. Acc. Chem. Res. 2010, 43, 1166-1175. [CrossRef] [PubMed]

5. Ricco, R.; Malfatti, L.; Takahashi, M.; Hill, A.J.; Falcaro, P. Applications of magnetic metal-organic framework composites. J. Mater. Chem. A 2013, 1, 13033-13045. [CrossRef]

6. Kurmoo, M. Magnetic metal-organic frameworks. Chem. Soc. Rev. 2009, 38, 1353-1379. [CrossRef] [PubMed]

7. Buso, D.; Jasieniak, J.; Lay, M.D.; Schiavuta, P.; Scopece, P.; Laird, J.; Amenitsch, H.; Hill, A.J.; Falcaro, P. Highly luminescent metal-organic frameworks through quantum dot doping. Small 2012, 8, 80-88. [CrossRef] [PubMed]

8. Sugikawa, K.; Nagata, S.; Furukawa, Y.; Kokado, K.; Sada, K. Stable and Functional Gold Nanorod Composites with a Metal-Organic Framework Crystalline Shell. Chem. Mater. 2013, 25, 2565-2570. [CrossRef]

9. Chandra, V.; Park, J.; Chun, Y.; Lee, J.W.; Hwang, I.-C.; Kim, K.S. Water-Dispersible Magnetite-Reduced Graphene Oxide Composites for Arsenic Removal. Am. Chem. Soc. 2010, 4, 3979-3986. [CrossRef] [PubMed]

10. Jahan, M.; Liu, Z.; Loh, K.P. A Graphene Oxide and Copper-Centered Metal Organic Framework Composite as a Tri-Functional Catalyst for HER, OER, and ORR. Adv. Funct. Mater. 2013, 23, 5363-5372. [CrossRef]

11. Deng, Y.; Qi, D.; Deng, C.; Zhang, X.; Zhao, D. Superparamagnetic High-Magnetization Microspheres with an $\mathrm{Fe}_{3} \mathrm{O}_{4} @ \mathrm{SiO}_{2}$ Core and Perpendicularly Aligned Mesoporous $\mathrm{SiO}_{2}$ Shell for Removal of Microcystins. Am. Chem. Soc. 2008, 13, 28-29. [CrossRef] [PubMed]

12. Buso, D.; Nairn, K.M.; Gimona, M.; Hill, A.J.; Falcaro, P. Fast Synthesis of MOF-5 Microcrystals Using Sol-Gel $\mathrm{SiO}_{2}$ Nanoparticles. Chem. Mater. 2011, 23, 929-934. [CrossRef]

13. Lu, G.; Li, S.; Guo, Z.; Farha, O.K.; Hauser, B.G.; Qi, X.; Wang, Y.; Wang, X.; Han, S.; Liu, X.; et al. Imparting functionality to a metal-organic framework material by controlled nanoparticle encapsulation. Nat. Chem. 2012, 4, 310-316. [CrossRef] [PubMed]

14. Mallakpour, S.; Madani, M. A review of current coupling agents for modification of metal oxide nanoparticles. Prog. Org. Coat. 2015, 86, 194-207. [CrossRef]

15. Maya, F.; Palomino Cabello, C.; Frizzarin, R.M.; Estela, J.M.; Turnes Palomino, G.; Cerdà, V. Magnetic solid-phase extraction using metal-organic frameworks (MOFs) and their derived carbons. TrAC Trends Anal. Chem. 2017, 90, 142-152. [CrossRef]

16. Zhao, X.; Liu, S.; Tang, Z.; Niu, H.; Cai, Y.; Meng, W.; Wu, F.; Giesy, J.P. Synthesis of magnetic metal-organic framework (MOF) for efficient removal of organic dyes from water. Sci. Rep. 2015, 5, 11849. [CrossRef] [PubMed]

17. Lee, H.-C.; Fantin, M.; Antonietti, M.; Matyjaszewski, K.; Schmidt, B.V.K.J. Synergic Effect between Nucleophilic Monomers and Cu(II) Metal-Organic Framework for Visible-Light-Triggered Controlled Photopolymerization. Chem. Mater. 2017, 29, 9445-9455. [CrossRef]

18. Zhao, H.-X.; Zou, Q.; Sun, S.-K.; Yu, C.; Zhang, X.; Li, R.-J.; Fu, Y.-Y. Theranostic metal-organic framework core-shell composites for magnetic resonance imaging and drug delivery. Chem. Sci. 2016, 7, 5294-5301. [CrossRef]

19. Abolhasani, J.; Khanmiri, R.H.; Ghorbani-Kalhor, E.; Hassanpour, A.; Asgharinezhad, A.A.; Shekari, N.; Fathi, A. An $\mathrm{Fe}_{3} \mathrm{O}_{4} @ \mathrm{SiO}_{2} @$ polypyrrole magnetic nanocomposite for the extraction and preconcentration of $\mathrm{Cd}(\mathrm{ii})$ and Ni(ii). Anal. Methods 2015, 7, 313-320. [CrossRef]

20. Stock, N.; Biswas, S. Synthesis of metal-organic frameworks (MOFs): Routes to various MOF topologies, morphologies, and composites. Chem. Rev. 2012, 112, 933-969. [CrossRef] [PubMed]

21. Shekhah, O.; Wang, H.; Zacher, D.; Fischer, R.A.; Woll, C. Growth mechanism of metal-organic frameworks: Insights into the nucleation by employing a step-by-step route. Angew. Chem. Int. Ed. 2009, 48, 5038-5041. [CrossRef] [PubMed]

22. Huo, S.H.; Yan, X.P. Facile magnetization of metal-organic framework MIL-101 for magnetic solid-phase extraction of polycyclic aromatic hydrocarbons in environmental water samples. Analyst 2012, 137, 3445-3451. [CrossRef] [PubMed]

23. Ke, F.; Yuan, Y.-P.; Qiu, L.-G.; Shen, Y.-H.; Xie, A.-J.; Zhu, J.-F.; Tian, X.-Y.; Zhang, L.-D. Facile fabrication of magnetic metal-organic framework nanocomposites for potential targeted drug delivery. J. Mater. Chem. 2011, 21, 3843-3848. [CrossRef] 
24. Mon, M.; Bruno, R.; Ferrando-Soria, J.; Bartella, L.; Di Donna, L.; Talia, M.; Lappano, R.; Maggiolini, M.; Armentano, D.; Pardo, E. Crystallographic snapshots of host-guest interactions in drugs@metal-organic frameworks: Towards mimicking molecular recognition processes. Mater. Horiz. 2018. [CrossRef]

25. Horcajada, P.; Chalati, T.; Serre, C.; Gillet, B.; Sebrie, C.; Baati, T.; Eubank, J.F.; Heurtaux, D.; Clayette, P.; Kreuz, C.; et al. Porous metal-organic-framework nanoscale carriers as a potential platform for drug delivery and imaging. Nat. Mater. 2010, 9, 172-178. [CrossRef] [PubMed]

26. Simon-Yarza, T.; Gimenez-Marques, M.; Mrimi, R.; Mielcarek, A.; Gref, R.; Horcajada, P.; Serre, C.; Couvreur, P. A Smart Metal-Organic Framework Nanomaterial for Lung Targeting. Angew. Chem. Int. Ed. 2017, 56, 15565-15569. [CrossRef] [PubMed]

27. McKinlay, A.C.; Morris, R.E.; Horcajada, P.; Ferey, G.; Gref, R.; Couvreur, P.; Serre, C. BioMOFs: Metal-organic frameworks for biological and medical applications. Angew. Chem. Int. Ed. 2010, 49, 6260-6266. [CrossRef] [PubMed]

28. Keskin, S.; Kızılel, S. Biomedical Applications of Metal Organic Frameworks. Ind. Eng. Chem. Res. 2011, 50, 1799-1812. [CrossRef]

29. Furukawa, H.; Cordova, K.E.; O'Keeffe, M.; Yaghi, O.M. The chemistry and applications of metal-organic frameworks. Science 2013, 341, 1230444. [CrossRef] [PubMed]

30. Mon, M.; Bruno, R.; Ferrando-Soria, J.; Armentano, D.; Pardo, E. Metal-organic framework technologies for water remediation: Towards a sustainable ecosystem. J. Mater. Chem. A 2018, 6, 4912-4947. [CrossRef]

31. Kobielska, P.A.; Howarth, A.J.; Farha, O.K.; Nayak, S. Metal-organic frameworks for heavy metal removal from water. Coord. Chem. Rev. 2018, 358, 92-107. [CrossRef]

32. Dias, E.M.; Petit, C. Correction: Towards the use of metal-organic frameworks for water reuse: A review of the recent advances in the field of organic pollutants removal and degradation and the next steps in the field. J. Mater. Chem. A 2016, 4, 3565. [CrossRef]

33. Bagheri, A.; Taghizadeh, M.; Behbahani, M.; Asgharinezhad, A.A.; Salarian, M.; Dehghani, A.; Ebrahimzadeh, H.; Amini, M.M. Synthesis and characterization of magnetic metal-organic framework (MOF) as a novel sorbent, and its optimization by experimental design methodology for determination of palladium in environmental samples. Talanta 2012, 99, 132-139. [CrossRef] [PubMed]

34. Zhang, K.D.; Tsai, F.C.; Ma, N.; Xia, Y.; Liu, H.L.; Zhan, X.Q.; Yu, X.Y.; Zeng, X.Z.; Jiang, T.; Shi, D.; et al. Adsorption Behavior of High Stable Zr-Based MOFs for the Removal of Acid Organic Dye from Water. Materials 2017, 10, 205. [CrossRef] [PubMed]

35. Zhao, Y.; Qiu, Z.; Huang, J. Preparation and Analysis of $\mathrm{Fe}_{3} \mathrm{O}_{4}$ Magnetic Nanoparticles Used as Targeted-drug Carriers. Chin. J. Chem. Eng. 2008, 16, 451-455. [CrossRef]

36. Mehdinia, A.; Einollahi, S.; Jabbari, A. Magnetite nanoparticles surface-modified with a zinc(II)-carboxylate Schiff base ligand as a sorbent for solid-phase extraction of organochlorine pesticides from seawater. Microchim. Acta 2016, 183, 2615-2622. [CrossRef]

37. Cavka, J.H.; Jakobsen, S.; Olsbye, U.; Guillou, N.; Lamberti, C.; Bordiga, S.; Lillerud, K.P. A new zirconium inorganic building brick forming metal organic frameworks with exceptional stability. J. Am. Chem. Soc. 2008, 130, 13850-13851. [CrossRef] [PubMed]

38. Ma, M.; Zhang, Y.; Yu, W.; Shen, H.; Zhang, H.; Gu, N. Preparation and characterization of magnetite nanoparticles coated by amino silane. Colloids Surf. A Physicochem. Eng. Asp. 2003, 212, 219-226. [CrossRef]

39. Wang, K.; Zhang, J.; Lou, L.; Yang, S.; Chen, Y. UV or visible light induced photodegradation of $\mathrm{AO}$ on $\mathrm{TiO}_{2}$ particles: The influence of inorganic anions. J. Photochem. Photobiol. A Chem. 2004, 165, 201-207. [CrossRef]

40. Song, X.; Zhao, B.; Gu, M.; Li, R. Adsorption Kinetics of Acid Orange 7 on $\mathrm{Nano}_{-} \mathrm{CeO}_{2}-\mathrm{TiO}_{2}$ in Water. J. Nanosci. Nanotechnol. 2015, 15, 7280-7284. [CrossRef] [PubMed]

41. Lohe, M.R.; Gedrich, K.; Freudenberg, T.; Kockrick, E.; Dellmann, T.; Kaskel, S. Heating and separation using nanomagnet-functionalized metal-organic frameworks. Chem. Commun. 2011, 47, 3075-3077. [CrossRef] [PubMed]

(C) 2018 by the authors. Licensee MDPI, Basel, Switzerland. This article is an open access article distributed under the terms and conditions of the Creative Commons Attribution (CC BY) license (http:/ / creativecommons.org/licenses/by/4.0/). 